13,3

\title{
Механизм образования углеродно-вакансионных структур в карбиде кремния при его росте методом замещения атомов
}

\author{
(C) C.A. Кукушкин ${ }^{1,2,3}$, A.B. Осипов ${ }^{2}$ \\ ${ }^{1}$ Институт проблем машиноведения РАН, \\ Санкт-Петербург, Россия \\ ${ }^{2}$ Санкт-Петербургский национальный исследовательский университет \\ инфрормационных технологий, механики и оптики, \\ Санкт-Петербург, Россия \\ ${ }^{3}$ Санкт-Петербургский государственный политехнический университет Петра Великого, \\ Санкт-Петербург, Россия \\ E-mail: sergey.a.kukushkin@gmail.com
}

(Поступила в Редакцию 19 марта 2018 г.)

\begin{abstract}
Изучен механизм образования углеродно-вакансионных структур в карбиде кремния $\mathrm{SiC}$ из кремниевых вакансий, которые неизбежно возникают при синтезе $\mathrm{SiC}$ из Si методом замещения атомов. Показано, что одному из 4 ближайших атомов углерода С выгодно переместиться на место кремниевой вакансии с понижением общей энергии на $1.5 \mathrm{eV}$ в случае политипа $3 \mathrm{C}$ и $0.9-1.4 \mathrm{eV}$ в случае политипа $4 \mathrm{H}$. При этом атому С необходимо преодолеть активационный барьер величиной $3.1 \mathrm{eV}$ в случае политипа $3 \mathrm{C}$ и $2.9-3.2 \mathrm{eV}$ в случае политипа 4Н. Данный переход осуществляется при синтезе $\mathrm{SiC}$ за счет тепловых флуктуаций, поскольку температура синтеза $T \approx 1200-1300^{\circ} \mathrm{C}$. Таким образом, углеродно-вакансионная структура представляет собой почти плоский кластер из 4 атомов С и связанную с ним углеродную вакансию с характерным диаметром $\sim 4 \AA$ на расстоянии $2.4 \AA$ от него. Методом упругих лент рассчитаны все характеристики данного превращения, а именно: энергетический профиль, путь превращения, переходное состояние, его частотный спектр, собственный вектор, отвечающий единственной отрицательной собственной частоте. Рассчитаны инфракрасный спектр (ИК) и диэлектрическая проницаемость $\mathrm{SiC}$, содержащего углеродно-вакансионные структуры. Обнаруженная недавно новая линия $960 \mathrm{~cm}^{-1}$ ИК спектра $\mathrm{SiC}$, выращенного методом замещения атомов, на основании проведенных расчетов однозначно отождествлена с колебаниями атомов С в углеродновакансионных структурах. Сделан вывод о том, что углеродно-вакансионные структуры стабилизируют кубический политип $\mathrm{SiC}-3 \mathrm{C}$.
\end{abstract}

Работа выполнена при финансовой поддержке РФФИ (грант № 16-29-03149-2016-офи). Работа выполнена при использовании оборудования Уникального стенда (УНО) „Физика, химия и механика кристаллов и тонких пленок“ ФГУП ИПМаш РАН.

DOI: $10.21883 /$ FTT.2018.09.46408.083

\section{1. Введение}

Как известно, карбид кремния $\mathrm{SiC}$ является одним из перспективных широкозонных полупроводников из-за различных уникальных свойств этого материала, таких как политипизм, высокая температура плавления, очень высокие твердость, теплопроводность, подвижность носителей заряда и т.д. [1,2]. Для интеграции карбида кремния и других широкозонных полупроводников, которые отлично сопрягаются с ним (таких как $\mathrm{GaN}$, $\mathrm{AlN}, \mathrm{AlGaN})$, в кремниевую электронику необходимо получать качественные эпитаксиальные слои $\mathrm{SiC}$ на кремниевых подложках [1-3]. Для решения этой задачи в работах [4-6] был разработан принципиально новый метод эпитаксии $\mathrm{SiC}$ на $\mathrm{Si}$ методом химического замещения атомов. Пленка $\mathrm{SiC}$ формируется на подложке $\mathrm{Si}$ за счет согласованного замещения каждого второго атома $\mathrm{Si}$ на атом С с помощью двухстадийной химической реакции

$$
\begin{aligned}
\mathrm{Si}(\text { crystal }) & +\mathrm{CO}(\text { gas }) \\
& =\mathrm{C}(\text { point defect in } \mathrm{Si})+V_{\mathrm{Si}}+\mathrm{SiO}(\text { gas }),
\end{aligned}
$$

$$
\mathrm{C}(\text { point defect in } \mathrm{Si})+V_{\mathrm{Si}}+\mathrm{Si}(\text { crystal })=\mathrm{SiC}(\text { crystal }),
$$

где $V_{\mathrm{Si}}-$ кремниевая вакансия. Она образуется за счет того, что продукт реакции $\mathrm{SiO}$ выводит часть атомов $\mathrm{Si}$ из системы. Квантово-химическая модель реакции (1)-(2) развита в работе [7].

Однако реальный рост эпитаксиальной пленки $\mathrm{SiC}$ по механизму (1)-(2) резко осложняется тем, что по мере роста пленки существенно нарастают механические деформации, несмотря на имеющиеся механизмы релаксации $[5,8]$. Карбид кремния, образующийся на первой стадии синтеза, сильно растянут, так как кубическая ячейка $\mathrm{SiC}$ размером $4.36 \AA$ образуется из кубической ячейки $\mathrm{Si}$ размером $5.43 \AA$. Затем происходит усадка и отрыв $\mathrm{SiC}$ от подложки кремния [5]. Согласно [5-7], когерентное сопряжение между решетками $\mathrm{Si}$ и $\mathrm{SiC}$ в этот момент нарушается и осуществляется только там, где каждая пятая ячейка $\mathrm{SiC}$ совпадает с четвертой ячейкой $\mathrm{Si}$. Происходит резкое изменение деформации, что вызывает сильный механохимический эффект [9], в результате которого часть атомов $\mathrm{Si}$, которые занимают больший 
объем по сравнению с атомами C, удаляется из пленки $\mathrm{SiC}$, образуя в кремниевой подрешетке вакансии. Кроме того, скорость химической реакции взаимодействия ансамбля точечных дефектов в кремнии (2) с образованием SiC, как показано в [10], существенно зависит от типа и степени легирования исходного кремния. В частности, в кремнии (111) p-типа проводимости будет выгодно образование структуры, в которой углерод, участвующий в реакции (2), не соединится полностью с кремниевой вакансией, а будет незначительно смещен относительно ее центра. Не вставший на свое место углеродный атом, незначительно смещенный в межузельное пространство, обладает свойством донорной примеси. В результате он будет иметь некоторый положительный заряд. Кремниевая вакансия будет обладать свойствами акцептора, т.е. получит отрицательный заряд. В результате возникнет электрический диполь, а в слое $\mathrm{SiC}$ возникнет электрическое поле [11]. Данная ситуация неустойчива, поскольку возникнет механохимический эффект, который приводит к тому, что часть атомов кремния будет смещаться по направлению к поверхности пленки. Это приведет к возникновению внутреннего электрического поля, которое будет направлено против электрического поля диполя, что ведет к дополнительному удалению атомов Si. Иными словами, карбид кремния, полученный из кремния методом согласованного замещения атомов, всегда будет содержать кремниевые вакансии [9]. Наличие кремниевых вакансий в $\mathrm{SiC}$ косвенно подтверждается анализом эллипсометрических спектров, которые однозначно свидетельствуют об избытке пиролитического графита и об избытке пустот примерно в одинаковых количествах [12]. Эллипсометрический анализ карбида кремния, выращенного другими способами, никогда не обнаруживал избытка графита.

Недавно анализ инфракрасных (ИК) спектров образцов $\mathrm{SiC} / \mathrm{Si}$, полученных методом согласованного замещения атомов, выполненный в двух экспериментальных группах, выявил новую линию $960 \mathrm{~cm}^{-1}$ как в спектрах поглощения, так и в спектрах пропускания [13-16]. Естественно, была высказана гипотеза, что данная линия связана с кремниевыми вакансиями, однако доказательства однозначной связи представлены не были.

В данной работе методом функционала плотности исследуется кристалл $\mathrm{SiC}$ политипов 3С и 4H, содержащий кремниевые вакансии. Показано, что после прыжка одного из 4 соседних атомов углерода на место кремниевой вакансии образуется более выгодная структура, состоящая из 4 атомов углерода и углеродной вакансии. Теоретический анализ ИК спектра получившейся углеродно-вакансионной структуры показал, что за счет колебаний $\mathrm{C}-\mathrm{C}$ связей в такой структуре должна появиться новая линия $970 \mathrm{~cm}^{-1}$, что очень хорошо соответствует экспериментальным данным. Поэтому на основании расчетов методом функционала плотности в настоящей работе делается вывод, что наблюдаемая новая линия $960 \mathrm{~cm}^{-1}$ действительно связана с кремниевыми вакансиями, образующимися в $\mathrm{SiC}$ за счет механохимического эффекта [9].

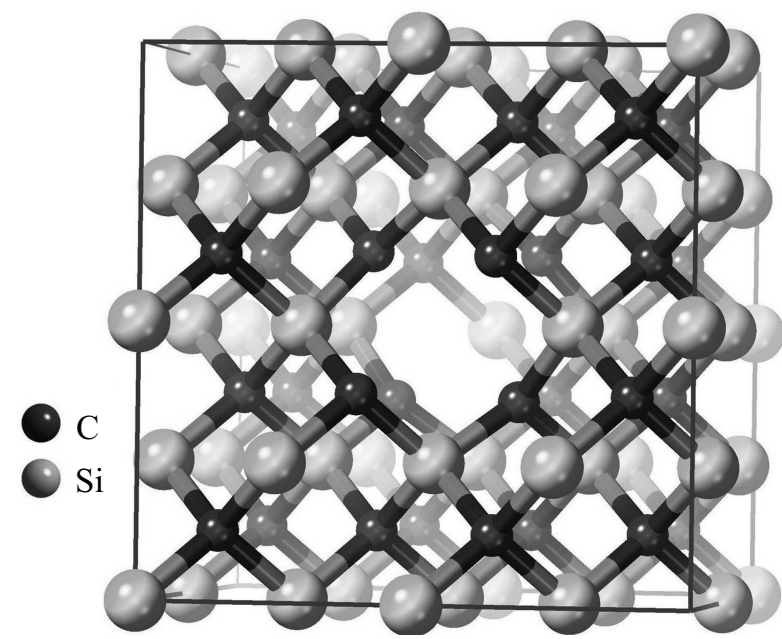

Рис. 1. Кремниевая вакансия в исследуемой суперъячейке из 31 атома $\mathrm{Si}$ и 32 атомов С. Длина ребра кубической суперъячейки равна $0.872 \mathrm{~nm}$.

\section{2. Анализ углеродно-вакансионной структуры методом функционала плотности}

Для того чтобы проанализировать свойства карбида кремния различных политипов, содержащего кремниевые вакансии, были использованы суперъячейки, содержащие достаточно большое количество атомов $\mathrm{Si}$ и $\mathrm{C}$. В частности, в случае кубического политипа $\mathrm{SiC}-3 \mathrm{C}$ использовалась суперъячейка $2 \times 2 \times 2$ кубического $\mathrm{SiC}$, состоящая из 64 атомов. Атом Si, находящийся в центре суперьячейки (в кубическом $\mathrm{SiC}$ все атомы $\mathrm{Si}$ идентичны), удаляется, таким образом, ячейка исследуемой системы состоит из 31 атома кремния и 32 атомов углерода (см. рис. 1). По всем трем измерениям на систему накладываются периодические граничные условия. Расстояние между соседними вакансиями в такой модели составляет $0.87 \mathrm{~nm}$, что должно гарантировать очень слабое взаимодействие между ними. В случае гексагонального политипа 4 Н исследуемая суперяъчейка состояла из $3 \times 3 \times 1$ элементарных ячеек $\mathrm{SiC}-4 \mathrm{H}$ и содержала 36 атомов кремния и 36 атомов углерода. После удаления одного атома $\mathrm{Si}$ среднее расстояние между соседними вакансиями составляет примерно $0.95 \mathrm{~nm}$.

Результат оптимизации геометрии системы при постоянном параметре решетки суперьячейки кубического $\mathrm{SiC}$ изображен на рис. 1. Вычисление проводилось методом функционала плотности в базисе плоских волн с использованием приближения псевдопотенциалов. Для этого использовался код Quantum Espresso [17]. Обменно-корреляционные эффекты вычислялись в рамках градиентного функционала PBESOL [18]. Для расчетов использовались нормосохраняющие псевдопотенциалы, приводящие к погрешности порядка $0.5 \mathrm{meV} /$ atom. Энергия обрезания плоских волн составляла $45 \mathrm{Ha}$. В обратном пространстве использовалась сетка по схеме 
Монхорста-Пака из $4 \times 4 \times 4$ точек, отвечающая расстоянию между точками $0.06 \AA^{-1}$.

Расчеты показывают, что этот минимум является всего лишь локальным. Если один из 4 атомов углерода, соседних с кремниевой вакансией, прыгнет на ее место, то после оптимизации геометрии системы ее энергия станет меньше на $1.5 \mathrm{eV}$. Фрагмент оптимизированной системы изображен на рис. 2, перемещение атома углерода в направлении $\langle 111\rangle$ показано стрелкой. Видно, что в плоскости (111) образуется симметричный, почти плоский кластер из 4 атомов углерода, длина связи $\mathrm{C}-\mathrm{C}$ равна $1.57 \AA$. Снизу на расстоянии $2.4 \AA$ в направлении $\langle 111\rangle$ находится углеродная вакансия, неразрывно связанная с углеродным кластером, поэтому такие образования мы называем углеродно-вакансионными структурами. Данная структура обладает симметрией $R 3 m$. Для вычисления энергетического профиля образования углеродно-вакансионной структуры, переходного состояния и активационного барьера применялся метод упругих лент (Nudged Elastic Band (NEB)) [18]. Данный метод позволяет определить так называемый путь с минимальным перепадом энергии (Minimal Energy Pathway (MEP)) [18]. Это такой путь превращения, при котором любое локальное изменение пути приводит к увеличению энергии системы в окрестности данной точки пути. Иными словами, это путь наискорейшего спуска из исходной конфигурации в конечную конфигурацию, т.е. наиболее вероятный путь перехода. В теории фазовых переходов первого рода $[8,19-21]$ координата вдоль такого пути из исходной фазы в конечную является параметром порядка данного фазового перехода. Соответственно, сечение поверхности потенциальной энергии вдоль пути превращения является энергетическим профилем данного превращения.

Для детального описания процесса формирования углеродно-вакансионных структур также использовался метод функционала плотности в приближении PBESOL

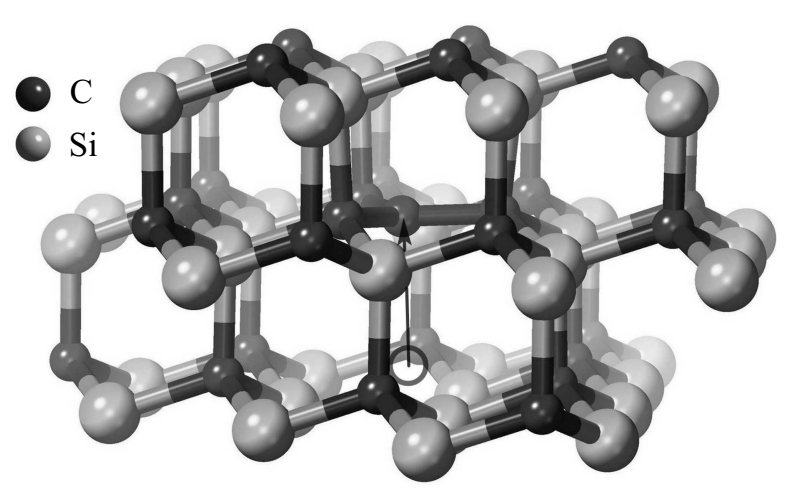

Рис. 2. Фрагмент суперъячейки с углеродно-вакансионной структурой. После прыжка атома С на место кремниевой вакансии образуется почти плоский кластер из 4 атомов С с длиной связи $\mathrm{C}-\mathrm{C}$, равной $1.57 \AA$. Снизу на расстоянии $2.4 \AA$ от этого кластера находится углеродная вакансия (пустота) с характерным размером $4 \AA$, неразрывно связанная с углеродным кластером.

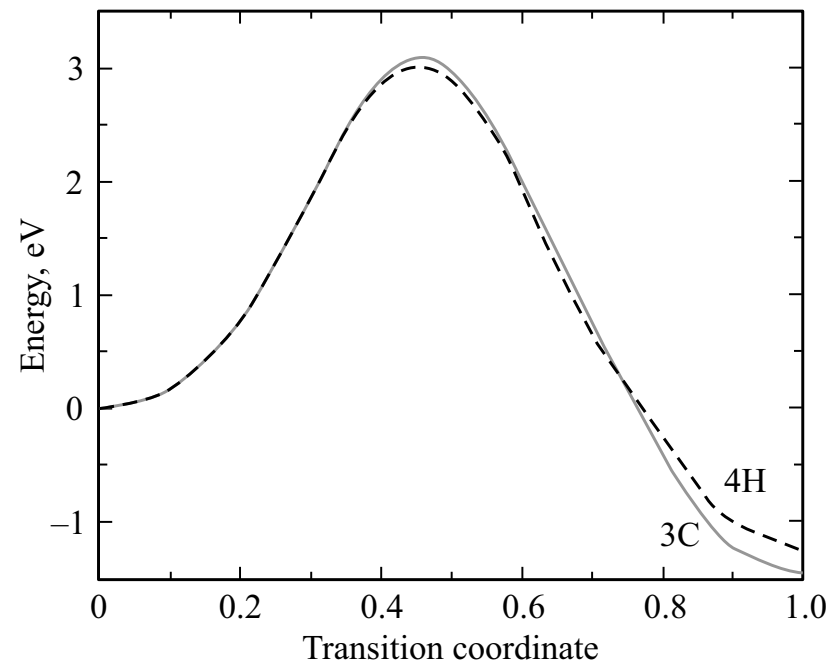

Рис. 3. Энергетический профиль превращения кремниевой вакансии в углеродно-вакансионную структуру, рассчитанный методом NEB [22] для двух политипов $\mathrm{SiC}$ : 3C (сплошная линия) и $4 \mathrm{H}$ (пунктирная линия). Для политипа $4 \mathrm{H}$ построен средний профиль для двух несимметричных (т.е. более выгодных) углеродно-вакансионных структур.

с использованием псевдопотенциалов и базиса плоских волн. Расчет методом NEB дает энергетический профиль образования углеродно-вакансионной структуры в кубическом $\mathrm{SiC}$, изображенный на рис. 3. Высота активационного барьера для кубического $\mathrm{SiC}$ равна $3.1 \mathrm{eV}$. Для того чтобы силы, действующие на атомы, были меньше $0.1 \mathrm{eV} / \AA$, потребовалось 4 итерации при 12 изображениях (images) в методе NEB. Переходное состояние данного процесса, соответствующее максимуму энергии в процессе формирования углеродновакансионной структуры, изображено на рис. 4. Оно, так же как и углеродно-вакансионная структура, обладает симметрией $R 3 m$. Отметим, что в работе [23] методами симметрийного теоретико-группового анализа также была показана возможность образования тригональной фазы $R 3 m$ в процессе превращения $\mathrm{Si}$ в $\mathrm{SiC}$. Стрелкой показано направление собственного вектора, отвечающего единственной отрицательной собственной частоте, равной $-580 \mathrm{~cm}^{-1}$. Именно в этой точке собственный вектор совпадает с путем превращения МЕР. Сравнительно небольшая величина отрицательной собственной частоты объясняется тем, что атом углерода не образует химической связи с соседними атомами (рис. 4) (расстояние до ближайших атомов $\mathrm{Si}$ равно $2.39 \AA \AA$ ).

Аналогичные расчеты были выполнены и для гексагонального политипа 4H, причем сетка по схеме Монхорста-Пака выбиралась из $3 \times 3 \times 2$ точек. Ключевое различие между политипами $3 \mathrm{C}$ и $4 \mathrm{H}$ заключается в том, что в $\mathrm{SiC}-4 \mathrm{H}$ с точки зрения симметрии атомы как $\mathrm{Si}$, так и С бывают двух типов, условно обозначаемые как $\mathrm{Si} 1, \mathrm{Si} 2, \mathrm{C} 1, \mathrm{C} 2$. Поэтому в $\mathrm{SiC}-4 \mathrm{H}$ существуют 4 типа неэквивалентных углеродно-вакансионных структур. Если прыжок атома С совершается в на- 


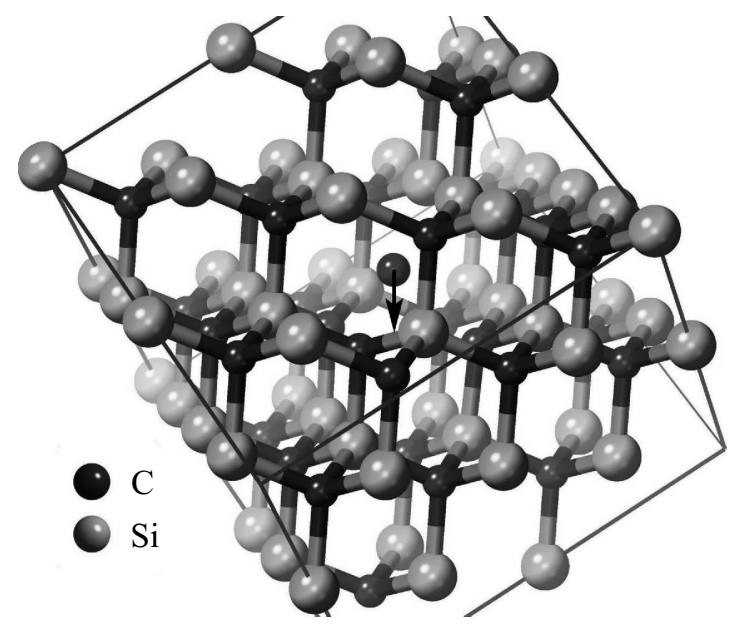

Рис. 4. Переходное состояние превращения в случае кубического $\mathrm{SiC}$, отвечающее максимуму энергии на рис. 3, с величиной энергетического барьера $3.1 \mathrm{eV}$. Стрелкой показан путь превращения (MEP) данной системы в углеродновакансионную структуру.

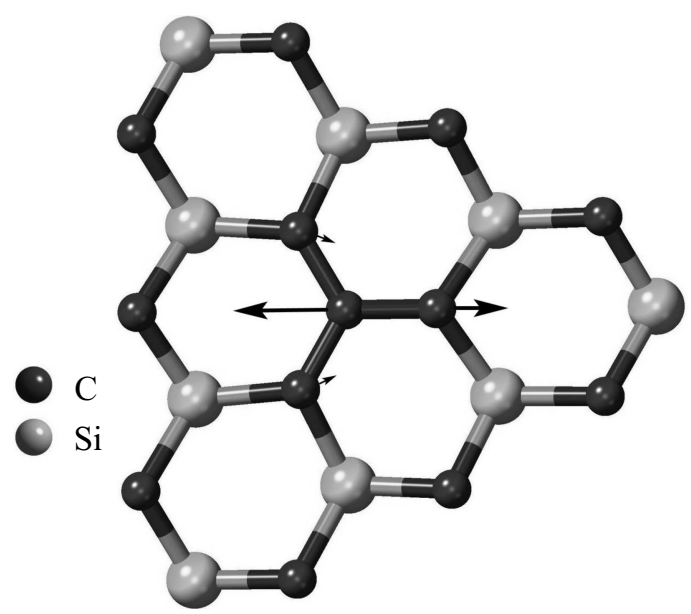

Pис. 5. Колебания углеродно-вакансионной структуры, соответствующие теоретической частоте ИК спектра $970 \mathrm{~cm}^{-1}$. Наибольшее движение совершает одна $\mathrm{C}-\mathrm{C}$ связь длиной $1.57 \AA$.

правлении $\langle 0001\rangle$, то углеродно-вакансионная структура обладает симметрией Р3М1. В противоположном случае симметрия структуры полностью исчезает, т.е. остается минимальная симметрия Р1, соответствующая периодическим граничным условиям. Расчеты показали, что несимметричная структура заметно выгоднее симметричной (примерно на $0.4 \mathrm{eV}$ ). Результаты расчетов примерно совпадают с результатами по 3C, главное отличие заключается в том, что выгода в образовании углеродно-вакансионной структуры несколько меньше и в среднем для 2 разных несимметричных углеродновакансионных структур равна $1.3 \mathrm{eV}$. Потенциальный барьер образования углеродно-вакансионной структуры для политипа $4 \mathrm{H}$ чуть ниже и в среднем для несим- метричных случаев равен примерно $3.0 \mathrm{eV}$. Средний энергетический профиль для 2 разных несимметричных углеродно-вакансионных структур в $\mathrm{SiC}-4 \mathrm{H}$ изображен на рис. 3.

Методом функционала плотности в приближении PBESOL с использованием псевдопотенциалов и базиса плоских волн был вычислен инфракрасный спектр системы с углеродно-вакансионными структурами. Его отличие от спектра чистого $\mathrm{SiC}$ для обоих политипов состоит в появлении новой линии $970 \mathrm{~cm}^{-1}$ и незначительном изменении частот основных линий. Колебания атомов, соответствующих частоте $970 \mathrm{~cm}^{-1}$, показаны на рис. 5 , сделанном в плоскости $\langle 111\rangle$ для $\mathrm{SiC}-3 \mathrm{C}$. Полученный результат полностью соответствует экспериментальным данным [13-16] по ИК спектрам карбида кремния, выращенного на кремнии методом химического замещения атомов. В частности, на рис. 6 приведены инфракрасные спектры на пропускание и на отражение образца $\mathrm{SiC}$ толщиной $80 \mathrm{~nm}$, выращенного на $\mathrm{Si}(111)$ при температуре $T=1250^{\circ}$ С. Новая линия $960 \mathrm{~cm}^{-1}$, которой нет на ИК
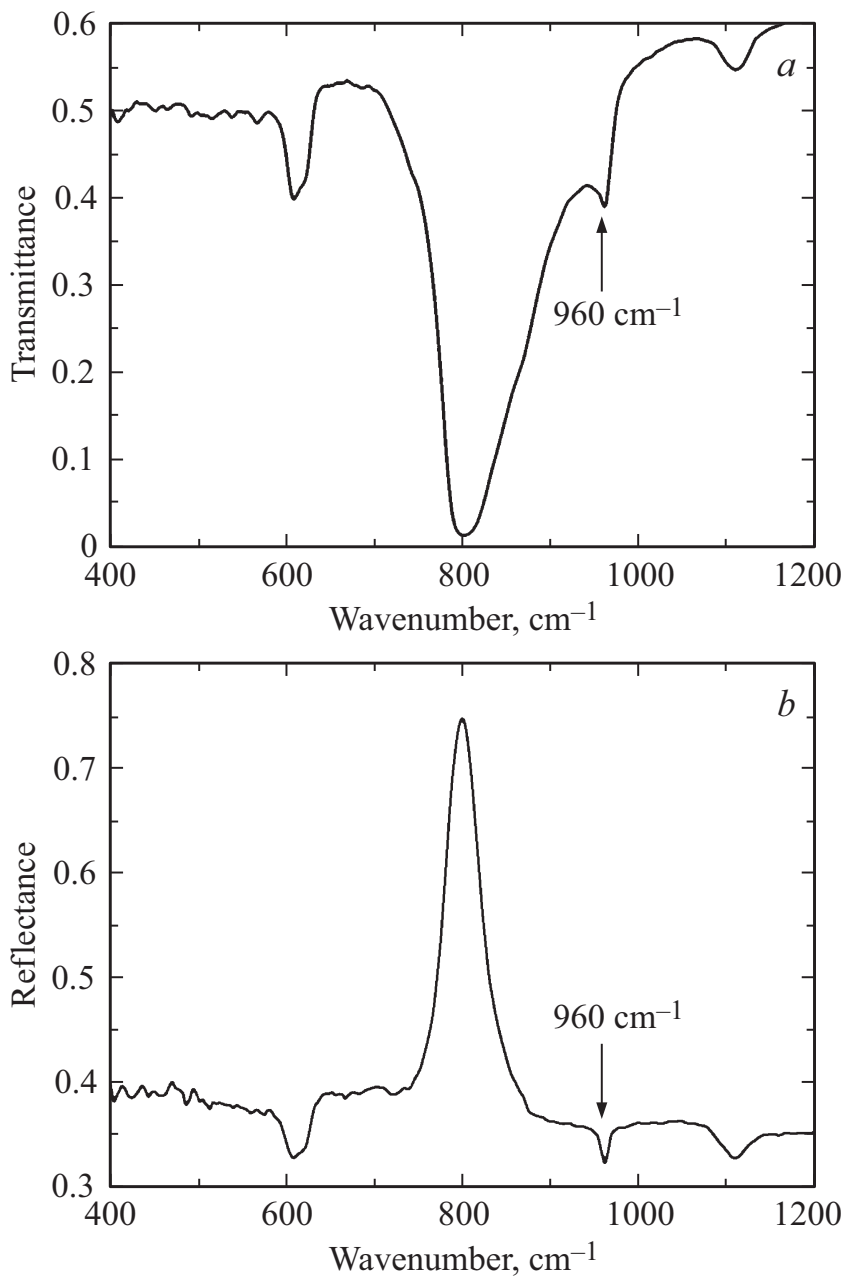

Pис. 6. ИК спектры на прохождение $(a)$ и отражение $(b)$ образца $\mathrm{SiC}$ толщиной $80 \mathrm{~nm}$, выращенного на $\mathrm{Si}(111)$ методом замещения атомов. Линия $960 \mathrm{~cm}^{-1}$ отождествляется в данной работе с колебаниями атомов углерода в углеродновакансионной структуре (рис. 5). 


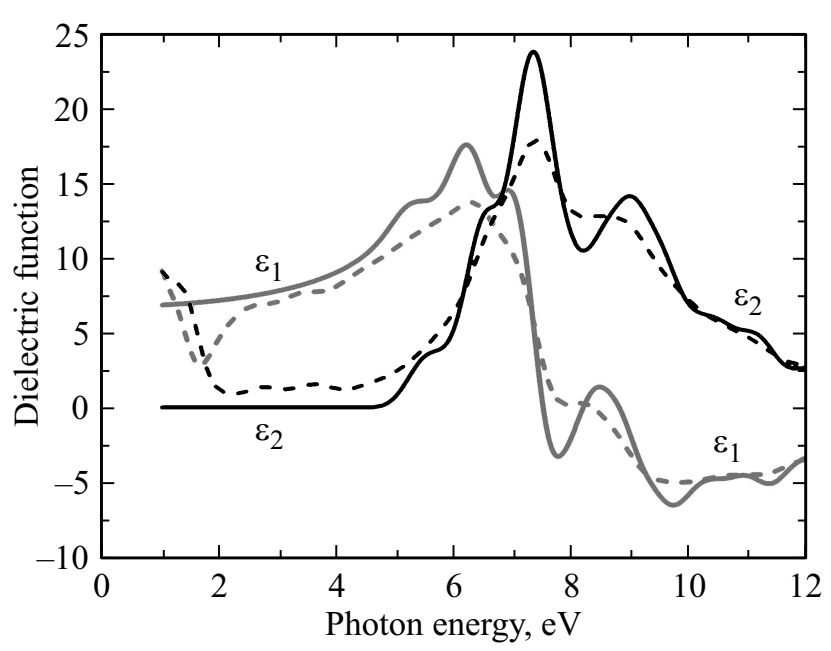

Рис. 7. Зависимость вещественной $\varepsilon_{1}$ и мнимой $\varepsilon_{2}$ частей диэлектрической проницаемости чистого $\mathrm{SiC}-3 \mathrm{C}$ (сплошная линия) и $\mathrm{SiC}-3 \mathrm{C}$, содержащего $2 \%$ (по объему) углеродновакансионных структур (штриховая линия), от энергии фотонов.

спектрах $\mathrm{SiC}$, полученного другим способом, отчетливо видна и там, и там.

Методом функционала плотности в приближении PBESOL с использованием псевдопотенциалов и базиса плоских волн также была вычислена диэлектрическая проницаемость $\mathrm{SiC}-3 \mathrm{C}$ с углеродно-вакансионной структурой. На рис. 7 представлена вещественная $\varepsilon_{1}$ и мнимая $\varepsilon_{2}$ части диэлектрической проницаемости суперъячейки кубического $\mathrm{SiC}$ с углеродно-вакансионной структурой, занимающей объемную долю $2 \%$, ориентированной по плоскости (111). Направление падения ординарного луча поляризованного света на кристалл было также по оси $\langle 111\rangle$. В случае гексагонального политипа 4Н разница диэлектрической проницаемости $\mathrm{SiC}$ с углеродно-вакансионной структурой и без нее аналогична случаю с $\mathrm{SiC}-3 \mathrm{C}$, но меньше по абсолютному значению.

\section{3. Обсуждение результатов и выводы}

Таким образом, в настоящей работе методом функционала плотности в приближении функционала PBESOL изучен процесс формирования улеродно-вакансионных структур в карбиде кремния. При выращивании $\mathrm{SiC}$ из $\mathrm{Si}$ методом замещения атомов образующийся $\mathrm{SiC}$ на первой стадии формирования сильно растянут, так как кубическая ячейка $\mathrm{SiC}$ размером $4.36 \AA$ образуется из кубической ячейки Si размером $5.43 \AA$ А. Затем происходит усадка и отрыв $\mathrm{SiC}$ от подложки кремния. Согласно [5-7], когерентное сопряжение между решетками $\mathrm{Si}$ и $\mathrm{SiC}$ в данном случае нарушается и осуществляется только в местах, в которых каждая пятая ячейка $\mathrm{SiC}$ почти совпадает с четвертой ячейкой $\mathrm{Si}$. B этот момент происходит резкое изменение деформации, что приводит к сильному механохимическому эффекту [10], в результате которого часть атомов $\mathrm{Si}$, которые занимают больший объем по сравнению с атомами C, удаляется из пленки $\mathrm{SiC}$, образуя в кремниевой подрешетке вакансии. Расчеты показывают, что на место кремниевой вакансии в $\mathrm{SiC}$ выгодно попасть одному из 4 соседних атомов C. При этом в случае кубического политипа $\mathrm{SiC}$ экономится энергия $1.5 \mathrm{eV}$, но необходимо преодолеть достаточно высокий активационный барьер $3.1 \mathrm{eV}$ (рис. 3). В случае гексагонального политипа $4 \mathrm{H}$ выигрыш энергии падает до 0.9-1.4 eV, причем несимметричная структура всегда выгоднее симметричной. Этот результат позволяет сделать вывод о том, что углеродно-вакансионные структуры стабилизируют именно кубический политип $\mathrm{SiC}$. Отметим, что данный вывод совпадает с выводом о влиянии углеродных вакансий на стабильность политипа 3C-SiC при гетерополитипной эпитаксии пленок карбида кремния методом сублимации на поверхности объемных кристаллов $\mathrm{SiC}$, сделанный А.А. Лебедевым и С.Ю. Давыдовым в работе [24].

Простейшие оценки показывают, что для преодоления активационного барьера достаточно нагреть систему примерно до $1100^{\circ} \mathrm{C}$. Поскольку рост $\mathrm{SiC}$ методом замещения атомов протекает при температурах $1200-1300^{\circ} \mathrm{C}$ [4-6], то этого достаточно, чтобы в $\mathrm{SiC}$ образовались углеродно-вакансионные структуры, состоящие из почти плоского кластера из 4 атомов С и кремниевой вакансии на расстоянии $2.4 \AA$ от него (рис. 2 и рис. 5 ). Переходное состояние, отвечающее максимуму энергии на рис. 3, также рассчитано и изображено на рис. 4. Расчет инфракрасного спектра получившейся углеродно-вакансионной структуры показал, что связи $\mathrm{C}-\mathrm{C}$ длиной $1.57 \AA$ (для сравнения длина связи $\mathrm{C}-\mathrm{C}$ в алмазе равна $1.54 \AA$ ) колеблются с частотой $970 \mathrm{~cm}^{-1}$ (рис. 5), причем интенсивность этой линии достаточно велика. Полученный результат прекрасно совпадает с экспериментальными данными по инфракрасному спектру образцов $\mathrm{SiC} / \mathrm{Si}$ (рис. 6), в которых зарегистрирована новая линия $960 \mathrm{~cm}^{-1}$ [13-16], которой нет в $\mathrm{SiC}$, полученном другими способами. Поэтому мы однозначно отождествляем данную линию $960 \mathrm{~cm}^{-1}$ с колебаниями $\mathrm{C}-\mathrm{C}$ связей в углеродно-вакансионных структурах, неизбежно возникающих при трансформации решетки Si в решетку $\mathrm{SiC}$ при замещении каждого второго атома $\mathrm{Si}$ на атом C.

Сравнение диэлектрической проницаемости $\mathrm{SiC}$ c углеродно-вакансионной структурой (с объемной долей $2 \%$ ) и без нее, т. е. чистого $\mathrm{SiC}$ (рис. 7), показывает, что углеродно-вакансионная структура делает $\mathrm{SiC}$ менее прозрачным, что также совпадает с экспериментальными данными [12]. Величина $\varepsilon_{2}$ в области энергий меньше $6 \mathrm{eV}$ становится заметно больше 0 , а при энергиях света меньше $2 \mathrm{eV}$ нарастает особенно сильно. Такое поведение $\varepsilon_{2}$ очень напоминает $\varepsilon_{2}$ монокристаллического пиролитического графита [25]. Именно этим объясняется тот факт, что эллипсометрические спектры реального $\mathrm{SiC}$, выращенного методом замещения атомов, требуют при моделировании включения пиролитического графита в $\mathrm{SiC}$ в рамках приближения эффективной среды [12]. 
Иными словами, $\mathrm{SiC}$, выращенный методом замещения атомов, всегда менее прозрачен, чем чистый $\mathrm{SiC}$, причем именно так, как будто он содержит пиролитический графит [12].

Авторы выражают глубокую благодарность С.А. Грудинкину за получение инфракрасных спектров пленок $\mathrm{SiC} / \mathrm{Si}$ (рис. 6).

\section{Список литературы}

[1] K. Takahashi, A. Yoshikawa, A. Sandhu. Wide Bandgap Semiconductors. Springer, Berlin (2007). 481 p.

[2] J. Fan, P.K. Chu. Silicon Carbide Nanostructures. Springer, Cham (2014). $336 \mathrm{p}$.

[3] T. Kimoto, J.A. Cooper. Fundamentals of SiC Technology. J. Wiley \& Sons, Singapore (2014). 551 p.

[4] S.A. Kukushkin, A.V. Osipov. J. Appl. Phys. 113, 024909 (2013).

[5] S.A. Kukushkin, A.V. Osipov. J. Phys. D 47, 313001 (2014).

[6] С.А. Кукушкин, А.В. Осипов, Н.А. Феоктистов. ФТТ 56, 1457 (2014).

[7] S.A. Kukushkin, A.V. Osipov. J. Phys. D 50, 464006 (2017).

[8] A.V. Osipov. J. Phys. D 28, 1670 (1995).

[9] С.А. Кукушкин, А.В. Осипов. Письма в ЖТФ 43, 13, 81 (2017).

[10] S.A. Kukushkin, A.V. Osipov, I.P. Soshnikov. Rev. Adv. Mater. Sci. 52, 29 (2017).

[11] А.С. Гращенко, Н.А. Феоктистов, А.В. Осипов, Е.В. Калинина, С.А. Кукушкин. ФТП 51, 651 (2017).

[12] С.А. Кукушкин, А.В. Осипов. Письма в ЖТФ 42, 4, 16 (2016).

[13] С.А. Грудинкин, В.Г. Голубев, А.В. Осипов, Н.А. Феоктистов, С.А. Кукушкин. ФТТ 57, 182 (2015).

[14] С.А. Грудинкин, С.А. Кукушкин, А.В. Осипов, Н.А. Феоктистов. ФТТ 59, 2403 (2017).

[15] С.А. Кукушкин, К.Х. Нусупов, А.В. Осипов, Н.Б. Бейсенханов, Д.И. Бакранова. ФТТ 59, 986 (2017).

[16] S.A. Kukushkin, K.Kh. Nussupov, A.V. Osipov, N.B. Beisenkhanov, D.I. Bakranova. Superlattices and Microstructures 111, 899 (2017).

[17] P. Giannozzi, S. Baroni, N. Bonini et al. J. Phys.: Condens Mater 21, 395502 (2009).

[18] J.P. Perdew, A. Ruzsinszky, G.I. Csonka, O.A. Vydrov, G.E. Scuseria, L.A. Constantin, X. Zhou, K. Burke. Phys. Rev. Lett. 100, 136406 (2008).

[19] A.V. Osipov. Thin Solid Films 261, 173 (1995).

[20] S.A. Kukushkin, A.V. Osipov. J. Chem. Phys. 107, 3247 (1997).

[21] С.А. Кукушкин, А.В. Осипов. ЖЭТФ 113, 2193 (1998).

[22] G. Henkelman, B.P. Uberuaga, H. Jonsson. J. Chem. Phys. 113, 9901 (2000).

[23] Ю.Э. Китаев, С.А. Кукушкин, А.В. Осипов. ФТТ 59, 30 (2017).

[24] А.А. Лебедев, С.Ю. Давыдов. ФТП 39, 296 (2005).

[25] G.E. Jellison, J.D. Hunn Jr., Ho Nyung Lee. Phys. Rev. B76, 085125 (2007)

Редактор Ю.Э. Китаев 